$$
\text { "mindakova" — 2007/8/9 - 13:44 — page } 1 \text { - \#1 }
$$

\title{
Task reformulation as a practical tool for formation of electronic digest of tasks
}

\author{
INGRID MiNĎÁKOVÁ and DušAn ŠvedA
}

Abstract. Creative thinking as well as thinking itself is being developed at active learning-cognitive activity of students. To make mathematic matter a subject of interest and work of students at classes, it is efficacious to submit it in a form of tasks. The tasks may be set up in a purposeful system of tasks by means of which reaching the teaching goals in the sense of quality and durability of gained knowledge may be more effective. A suitable means for presentation of tasks with their characteristics (as e.g. didactic function and cognitive level) as well as task systems themselves is an electronic digest of tasks as a database. The analysis of textbooks and digests of tasks commonly used at schools in Slovakia shows that they do not include all the types of tasks necessary for setting up complete (in the sense of didactic functions) task systems. One of the most important methods used for formation of the missing tasks is reformulation of tasks. The individual strategies of task reformulation are explained in details on examples in this article.

Key words and phrases: mathematical task, task system, criteria for mathematical task classification, electronic digest of tasks, task reformulation.

ZDM Subject Classification: C33, C34, D43, D44, R23, R24, U23, U24.

\section{Introduction}

Creative thinking along with thinking itself is being developed during active learning and cognitive activity of students. Therefore every teacher looks for some new methods and forms to draw the students' interest in learning activity. To raise and keep the activity as well as "hunger" of students for knowledge, the teacher 


$$
\text { "mindakova" — 2007/8/9 - 13:44 - page } 2 \text { - \#2 }
$$

ought not mediate the knowledge to students in a complete form but they ought to provide students with tasks involving unknown knowledge and proceedings, they should motivate and regulate searching for ways and means of solving the tasks, since searching for them students gain new knowledge and skills and at the same time develop their abilities of problem solving.

Learning of reality is a complex process. Students should get acknowledged with mathematics through activities characteristic for mathematics. They should receive complete pieces of knowledge at minimum, while at the same time they should be as active as possible in the learning process itself, since activity is an inseparable part of conscious accepting the knowledge. Active cognitive process can lead to development of logical thinking, ability to formulate and solve problems as well as the ability of independent work.

\section{Task systems}

Tasks and their solving are the primary content of teaching mathematics. They are used in all the stages of teaching process, and that means that they fulfil various didactic functions. Solving the tasks students get acknowledged with methods of work in the given area of human cognition and knowledge of mathematics is an irreplaceable tool for solving important problems of everyday life.

To make the mathematic matter a subject of interest and work of students at classes it is efficacious to submit it in a form of tasks, and not in a form of ready-made knowledge. Each task involves at least one didactic function. The tasks may be set up in a purposeful system of tasks that should draw the interest, activate and regulate activity of students.

Along with assigning a group of tasks that students solve in a certain order, a system of their activity is defined, the structure of cognitive process. A group of tasks where one task itself or more tasks altogether fulfil a certain didactic function in accordance with tuition aims, cognitive process structure and teaching process conditions is called a task system (see [32]).

The publication (see [32]) describes in detail what a task system is as well as the proceedings of its elaboration, it offers samples of systems of task that have been attested and approved in use, and also a detailed description of pedagogic experiments that have been performed in natural conditions at apprentice schools. However, since this handbook is published in Slovak language, we at least give a summary of the acquired knowledge here. 


$$
\text { "mindakova" — 2007/8/9 - 13:44 — page } 3 \text { - \#3 }
$$

The most suitable as well as approved-in-use proceeding at forming a task system is as follows:

(1) logical and didactic analysis of subject matter (a complex analysis of subject matter consists of

(a) search for the answer to the question What to teach?, i.e.

- clearing out the logical structure of the subject matter (notions, theorems, solving modes)

- formulation of teaching aims

- concretization of teaching aims

(b) search for the answer to the question How to teach? (selection of methods and forms of teaching))

(2) setting up the teaching aims and their concretization by help of type tasks

(3) determining the succession of adoption of subject matter individual elements

(4) formation of the task system itself where tasks gradually represent concrete didactic functions

Examples of forming a task system for a particular topic exceed the framework of our article. Setting up the task system for subtopics of Exponential functions, Quadratic equations, Graphs of quadratic equations (incl. absol. value), graph reading is described in the works of authors (see [23, 25, 32]).

Experience used in this article have been obtained from a pedagogic experiment aimed to formation and approval of task systems at teaching mathematics. The outcomes of the accomplished experiment show that teaching mathematics by means of task systems is more efficient than teaching by means of tasks in textbooks that we analysed (the list of these is shown in [24]). Reaching the teaching goals by means of task systems is, in the sense of quality and durability of acquired knowledge, more efficient. This claim comes out of the results of entry and final tests as well as the tests that were carried out after a period of time from finishing the experiment in tested and control classes. The performance of students in experimental classes was higher than the performance of students in control classes even after a period of time.

Despite all the strengths that teaching by means of task systems brings, we realize that there are also some obstacles to application of this method in practice. Suitable universal task systems do not exist since every system should reflect both inner as well as outer conditions for their implementation. Thus one of the obstacles is time demanding for preparation and realization of the mentioned way of teaching. Therefore in order to ease and quicken preparation of 


$$
\text { "mindakova" — 2007/8/9 - 13:44 — page } 4 \text { - \#4 }
$$

teachers for the class we have decided to make up a practical tool for presentation of mathematical tasks, their characteristics as well as task systems themselves. This tool is an electronic digest of tasks as a database accessible on the Internet.

\section{Electronic digest of tasks}

The described digest of tasks has been formed since 1993 at the Department of Mathematics and Informatics Didactics, Faculty of Science of P. J. Šafárik University in Košice (Slovakia). The digest protected by a password is accessible at the address http://sis.science.upjs.sk/matematika/zbierka/. At present the digest is being used by teachers of 9 secondary schools in Košice and eastern Slovakia.

In order to find out about the status of electronic digests of tasks development, we have been searching the Internet pages of secondary schools and universities, their teachers as well as firms offering tuitionary programmes. The found references (http://btmdx1.mat.uni-bayreuth.de/smart, http://www .math4u.de/, http://www.mia.sk, http://vazka.sk/matematika/pisomky.html, ...) prove that there are not many of electronic digests of tasks. We found many internet pages of mathematics teachers who offer various recommendations on teaching some thematic units of mathematics, lists of links to mathematics software as well as a lot of other information, however, we only found very few electronic digests of tasks containing tasks of more topics.

Analysis of these digests of tasks from the point of view of contents and classification of tasks has confirmed that task classification in any of the mentioned available electronic (as well as printed) digests of tasks comes to an end at the topic or subtopic a task belongs to, in rare cases at an element of the subject matter. However, from such a classification of tasks, the teachers will not acquire the information, a very valuable for them, on demandingness of the task as well as on the stage of the teaching process this task should be used at.

\section{Criteria for task classification in the digest}

In literature (see $[2,7,9,13,14,15,16,17,20,21,22,26,34,38]$ ) we meet various typologies of tasks in dependence on the chosen criterion. The most common criteria for the task classification include: topic, task contents, task formulation, didactic aims monitored by the task, mathematical symbols in the 


$$
\text { "mindakova" — 2007/8/9 - 13:44 — page } 5 \text { - \#5 }
$$

task setting, the stage of teaching process at which the task can be used, openness of the solution, subject i.e. a student, solving method, cognitive level, necessary level of knowledge essential for task solving, task demandingness and many others.

As the most suitable task classification for an electronic digest of tasks in the mathematics field that meets the requirements for task system formation appears to be the criteria structure from the digest of tasks by I. Bobovníková (see [4]) and M. Fečo (see [12]). This model of task classification has been taken over with some modifications into electronic digest of tasks being formed.

The tasks are divided in the database according to five criteria: The first criterion is division of tasks according to the topic (e.g. Functions; Equations, Inequalities and their systems; Planimetry; ...).

The second criterion for task division in this digest is a subtopic (the topic of Functions includes subtopics as e.g. Linear function, Quadratic function, Linear fractional function, ...).

We can specify 3 essential elements in the mathematics subject matter: notions, mathematical theorems and ways (methods) of solving the basic categories of tasks. The third criterion for task classification are elements of mathematics subject matter (e.g. in the framework of the subtopic of Linear function, the following elements of the subject matter are specified - Definition of linear function, $D(f), H(f)$; Graphs of linear functions (abs. value incl.), graph reading; Constant function; Continual proportion; ...).

When selecting the tasks for the lesson it is necessary to come out of the principle of cognitive process as well as the principle of teaching process with its inner and outer conditions. These requirements can be expressed by the means of didactic functions that particular tasks fulfil. For that reason, didactic functions of tasks are the fourth criterion. According to D. Šveda (see [32]) we distinguish the following didactic functions:

(1) tasks for motivation of learning and cognitive activity of students

They are the tasks associated with future vocation of students and tasks from the students' sphere of interest. Problem tasks with both non-mathe-matical as well as mathematical content may also have a motivating effect.

(2) tasks for updating the subject matter

This involves tasks for revising the single parts of subject matter submitted earlier that will be necessary to be used when acquiring new subject matter elements. 


$$
\text { "mindakova" — 2007/8/9 - 13:44 — page } 6 \text { - \#6 }
$$

(3) preparatory tasks

This criterion includes tasks aimed to explanation and primary acquirement of mathematical notions, mathematical theorems and solving procedures of mathematical tasks. These precede the utterance of theorems and definitions. The effect of these tasks from the time point of view is very short, it refers to the nearest subject matter element being acquired.

(4) tasks for acquiring the concept definition, theorem formulation, and solving procedure

We can rank here tasks focused on syntactic and semantic aspect of single subject matter elements, as well as tasks serving for acquiring basic skills for work with notions and theorems.

(5) tasks for strengthening the subject matter

This includes tasks that have varying difficulty and help strengthen and practise acquired knowledge and skills.

(6) tasks for application of subject matter outside mathematics

These are the tasks that solve situations of real life and practice. Tasks from other subjects whose solution requires mathematical apparatus may also be included here.

(7) tasks for application of subject matter inside mathematics

This group includes tasks where new subject matter is applied in various areas of mathematics, and also tasks for adoption of bindings between older and newer subject matters.

(8) tasks of propedeutic character

Here we can rank the tasks of developing character (e.g. argument tasks) but also the tasks preparatory for adoption of subject matter elements in following topical units. From the time point of view, the effect of tasks of propedeutic character is longer than effect of preparatory tasks.

(9) tasks for revision and systematization of subject matter

These are tasks to solve which it is necessary to use the knowledge of more interlocked thematic units. The tasks are of a complex and generalizing character and they are used at the end of a tuition unit, topic or thematic unit.

The fifth criterion of the task division we have used in the digest is a level of cognitive processes that are developed by the task. This model of task classification elaborated by M. Zelina (see [41]) and coming out of the cogni- 


$$
\text { "mindakova" — 2007/8/9 - 13:44 — page } 7 \text { — \#7 }
$$

tive processes classification according to S. B. Bloom (see [3]) defines 6 levels of cognitive processes:

(1) perception

The tasks that we use to find out how precisely the student perceives the task setting, since further thinking operations are based on the precise understanding of the task. We also watch if the student have not missed something essential and also if they perceive flexibly. Some collocations may appear in the tasks: watch the table, graph, ...; what can you see in the picture; ...

(2) memory

We rank here the tasks serving for memory reproduction of knowledge (formulas, theorems, definitions and proceedings). They can follow directly after uttering the theorem or definition. We can use the following collocations in these tasks: write the formula, proceeding, ...; say ...; name ...; define ...; describe ...

(3) lower convergent processes

Tasks, solutions of which include analysis, deduction, induction, immediate causation and some methodological skills are ranked into this group. They are the tasks with an occurrence of words as: give a reason for, analyse, what all do we have here?, count according to the formula, complete, use for solving, deduce, induce, specify the conditions, how have you come to this?, what will the proceeding be?, what will you do now?, what steps will it need?, where can you find it?, give a proof (a simple proof for immediate application of the known proceeding).

(4) higher convergent processes

We can rank here tasks for solving which it is necessary to use synthesis, analogical thinking, generalization, and application of subject matter on new cases. The following collocations may be used in these tasks: how can you explain it?, deduce the conclusion, deduce the theorem, work out an analogical task, what is the opposite?, say in your own words, describe, put in relation, interpret, compare, put in contrast, check the opposite, use in this connection.

(5) evaluative thinking

Tasks using complex thinking processes to evaluate facts, proceedings and results of activities are assigned here. Students present their own opinions. The introductions to tasks are as follows: make up a norm (criterion) for evaluation, which are good, bad, what is correct and what is incorrect, find a 


$$
\text { "mindakova" — 2007/8/9 - 13:44 — page } 8 \text { - \#8 }
$$

mistake, which one you like, gradate from good to bad, consider according to ..., sum up the result, grade, give an evidence, assess the evidence, evaluate according to, assess according to your own feeling, are these solutions good, correct?

(6) creative, divergent thinking

We rank here tasks developing creative divergent thinking, namely the tasks solving problem situations, and tasks in which it is necessary to determine alternative or all the possible solutions. They contain collocations as: make up, suggest, invent, explore and explain, suggest as many hypothesis as possible, transform, use a metaphor, use an analogy, think of all the different ways, in what other way, make up as many as you can, consider as many consequences as possible, how many ways are possible, develop, in what ways you can improve, suppose, make a new, ...

To conclude the description of criteria it is necessary to mention that one task can be ranked to more topics, subtopics, elements of subject matter and to various didactic functions. Besides other reasons, the possibility of multiple inserting of a task in the digest comes out firstly of a subjective view on insertion of tasks, and secondly of more proceedings for task solving. We find multiple occurrence of a task in the electronic digest to be a great asset in comparison with classical (paper) digests of tasks where the task only appears once. The review of all the occurrences of a particular task in the digest is possible to be obtained in the detailed display of the task that also includes (besides other) the task solution guide as well as the task solution. Using modern informatics technologies for forming the electronic digest of tasks this aspect can be implemented easily. Concrete examples of a multiple occurrence of a task in the digest will be described later.

A task solving more didactic functions is assigned to all of these functions. A task developing a certain level of cognitive processes also develops all the lower levels of cognitive processes. Therefore when ranking the tasks, we have often used only the highest possible level of cognitive processes that is developed by the task.

We realize that classification of tasks according to the didactic function and cognitive level is often subjective (and therefore also demanding) and it depends not only on the task formulation but also on knowledge and experience of students, conditions of tuitional process as well as the approach of the teacher to organization of learning and cognitive activity of students. This is the reason why the classification of tasks according to didactic function and cognitive level from 


$$
\text { "mindakova" - 2007/8/9 - 13:44 — page } 9-\# 9
$$

the point of view of planning activity of a teacher is so important and very useful.

The electronic digest of tasks is being completed according to the chosen criteria so that it allows to set up task systems that after potential small modifications might be applied directly at a lesson. The strongest stress is put on completing the tasks according to didactic functions that are a key element for formation of task systems.

\section{Missing types of tasks}

While assembling the digest, we have met many problems. Perhaps the greatest one is a lack of tasks that would fulfil various didactic functions. This claim is based upon the analysis of textbooks and digests of tasks commonly used at secondary schools (see the list in [24]) as well as books preparing the students for the new form of school-leaving examination (see $[1,6,27]$ ). The mentioned textbooks and digests of tasks have been analysed with regard to occurrence of tasks fulfilling various didactic functions in the topics Functions and Equations, inequalities and their systems. After consultations with teachers each task was unequivocally assigned just one didactic function. The complete analysis is elaborated in (see [24]), and the result is that analysed textbooks and digests of tasks contain a great deal of routine, algorithmic tasks for strengthening the subject matter (48.85\%), rather many tasks for motivation of learning and cognitive activity of students and tasks for application of subject matter (26.87\%) and tasks for revision and systematization of subject matter (16.39\%), however, only there are only few tasks for updating the subject matter (0.3\%), preparatory tasks (2.84\%), tasks for acquiring the concept definition, theorem formulation, and solving procedure $(3.25 \%)$, as well as tasks of propedeutic character (1.5\%). And because the last mentioned types of tasks are essential for providing quality, effective learning and cognitive activity of students, it is necessary to eliminate this shortage of tasks.

We have chosen two methods to form tasks covering all the didactic functions:

(1) creation of "new tasks" - firstly, it means creation of absolutely new tasks. They are usually the tasks that do not occur in the digests of tasks, however, they are often used by teachers at mathematics lessons at the stage of subject matter updating, at preparatory stage as well as at the stage of subject matter adoption. Secondly, it is a new, different assigning in the framework of topics, subtopics and subject matter elements of secondaryschool mathematics.

(2) reformulation of tasks already existing 


$$
\text { "mindakova" - 2007/8/9 - 13:44 — page } 10-\# 10
$$

\section{Task reformulation}

In literature (see $[5,10,18,19,28,29,30,31,33,35,36,37,39,40]$ ), we meet different views on task reformulating. From simple changes in task setting to sophisticated conceptions for task variations. Task reformulation can be looked at from more aspects: task reformulation as a method for creation of new tasks, as a method for formation of task groups, as a method for task solving, as a method for logical and creative thinking development or as a method used at tuition.

We see task reformulation as the above mentioned method for providing missing types of tasks, as a method for changing the task quality, as a method for increase or decrease of task's difficulty, as a method for creation of non-standard, divergent tasks so necessary for logical thinking development.

Despite modernizing trends of mathematics teaching in the world, Slovakia likewise, closed, convergent tasks are still very popular, e.g. at school-leaving examinations. On the one hand, we do not want to deny the importance of this type of tasks at lessons, and therefore we do not avoid them in this article. On the other hand, we present several ways which help to create open, divergent tasks that can meet the demands of new trends in mathematics teaching.

The nearest to our model of task reformulating is the one of M. Cirjak (see [8]) and the model of H. Schupp (see [28]). M. Cirjak describes task reformulating from the point of view of standard tasks' creative potential increase. H. Schupp assembled a complex - but as he writes by no means a complete and disjunctive - system of task reformulating methods. Teachers should get acknowledged with this model containing 24 task reformulating methods, and then apply it at classes altogether with their students. In our opinion, some of the methods (e.g. extremalization and observation of extreme cases, re-orientating and turning, ...) are very similar and only distinguishable with difficulties, and thus the number of elements of this conception increases unnecessarily. A model of many components may be non-transparent in use and clumsy and therefore it can cause considerable problems. In our article, we offer a simpler system of methods which is a more general view on task reformulation. In comparison with Schupp's model, our model is disjunctive and therefore it allows to name the change of task unequivocally. This model should be easily applicable in practice even for a common teacher. Just to compare, while describing our methods, we also submit Schupp's methods that intersect with our methods that are just being described. 


$$
\text { "mindakova" — 2007/8/9 — 13:44 — page } 11 \text { — \#11 }
$$

\section{Three methods of task reformulation}

When forming the tasks, we apply the following three methods of task reformulation:

\section{(1) Change of a condition in the task setting \\ (2) Change of the task plot \\ (3) Creation of a reversed task}

\section{Change of a condition in the task setting}

The method of condition change in the task setting includes Schupp's methods such as a negligible change, analogy, generalization, specialization, observation of extreme cases, extremalization, change of figures, fulfilling the gap, adding a task, giving a task a sense, visualization, other evaluation and criticism.

Changing a condition in the task setting it is possible to achieve a change of task classification according to the topic, subtopic and subject matter element, but also a change of didactic function and cognitive level, it is also possible to increase task quality, i.e. to make a divergent task from a convergent task, to change the number of proceedings for the task solution ....

We will describe this way of task reformulation on the following examples:

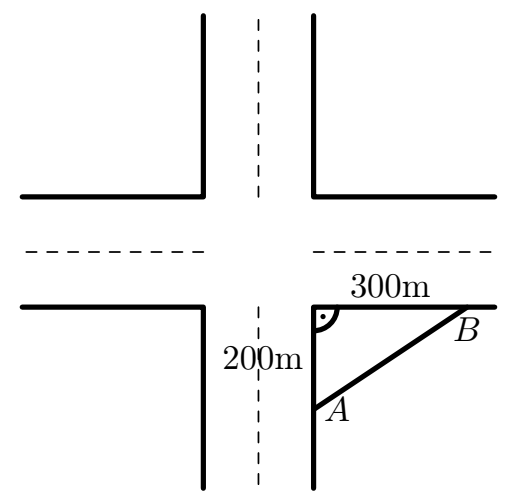

Figure 1

Task 1: A bus is going from a bus stop $A$ to a bus stop $B$ (see Figure 1). Can a boy catch the bus that he missed in $A$ if it is going at an average 


$$
\text { "mindakova" — 2007/8/9 — 13:44 — page } 12 \text { — \#12 }
$$

speed of $36 \mathrm{~km} / \mathrm{h}$ and the boy is running along a short-cut at a speed of $10.8 \mathrm{~km} / \mathrm{h}$ ?

Ranking Task 1 into the digest is as follows:

Topic: Planimetry

Subtopic: Triangle

Element of subject matter: Euclid's and Pythagorean Theorems

Didactic functions:

tasks for motivation of learning and cognitive activity of students

tasks for strengthening the subject matter

tasks for application of subject matter outside mathematics

Cognitive level:

lower convergent processes

higher convergent processes

We will only describe in details the considerations for tasks classification according to appointed criteria at Task 1. As for other tasks, we will only confine ourselves to the aspects we would like to draw the attraction to.

In one of possible solving procedures for Task 1 Pythagorean Theorem can be used. Therefore this task is ranked to the subject matter element of Euclid's and Pythagorean Theorems in the topic of Planimetry, and in its framework to the subtopic of Triangle. Ranking of Task 1 to didactic functions depends on the level of teaching process where the task can be used. If the students are not acknowledged with the Pythagorean Theorem, this task may serve to motivate the learning and cognitive activity of students. If the students understand the mentioned theorem, this task may be used at the stage of strengthening the subject matter. Since the above mentioned task is a wording task from practice, the task also meets the didactic function of application of subject matter outside mathematics. The level of cognitive processes that are developed by the task comes out of proceedings chosen for the tuition. If the task is applied as a tasks for motivation of learning and cognitive activity of students, it develops higher convergent processes, however, if it is assigned to the tasks for strengthening the subject matter or to tasks for application of subject matter outside mathematics, i.e. similar tasks have already been solved, it develops lower convergent processes.

In what way will the classification of Task 1 be changed according to the appointed criteria if there is not a condition in the task that the roads are perpendicular to each other? 


$$
\text { "mindakova" — 2007/8/9 — 13:44 — page } 13 \text { — \#13 }
$$

The task cannot be solved by the Pythagorean Theorem, it is necessary to use the law of cosine, i.e. the classification is as follows:

Topic: Trigonometry

Subtopic: Trigonometry

Element of subject matter: The laws of sine and cosine (solution of a scalene)

\section{Didactic function:}

tasks for motivation of learning and cognitive activity of students tasks for strengthening the subject matter

tasks for application of subject matter outside mathematics

\section{Cognitive level:}

lower convergent processes

higher convergent processes

A simple reformulating of the task has changed its classification according to the topic, subtopic and element of subject matter. Ranking to didactic functions and cognitive levels can be reasoned in a similar way as for Task $\mathbf{1}$.

However, the change of Task 1 classification in the framework of the topic of Planimetry, the subtopic of Triangle and the subject matter element of Euclid's and Pythagorean Theorems with regards to the didactic function. The task becomes a task of propedeutic character to the law of cosine.

If students are submitted a task from a topic that has not been "officially" gone through, individual solving strategies might be used. If the teacher going through the law of cosine goes back to solving of Task 1, a link between a new and old subject matters arises and at the same time implicit revision is going on.

This was one of the examples how we complete missing types of tasks, especially preparatory tasks, tasks for acquiring the concept definition, theorem formulation, and solving procedure and tasks of propedeutic character into the digest of tasks that is being made.

On the following example we present one of the advantages of electronic digest of tasks, i.e. a multiple occurrence of a task in the digest.

Task 2A: Two concurrent lines $a, b$ are scheduled in a plane, and a point $M$ not lying on either of the lines. Draw a line $p$ going through the point $M$ and the intersection point $R$ of the lines $a$ and $b$.

The wanted line will be drawn by linking two points, therefore the classification of the task is as follows:

Topic: Planimetry 


$$
\text { "mindakova" — 2007/8/9 — 13:44 — page } 14 \text { — \#14 }
$$

Subtopic: Basic concepts

Element of subject matter: Point, straight line, plane and relations among them

Didactic function: tasks for strengthening the subject matter

Cognitive level:

perception

lower convergent processes

This simple task may be reformulated in the following way:

Task 2B: Two concurrent lines $a, b$ are scheduled in a plane, and a point $M$ not lying on either of the lines. Draw a line $p$ going through the point $M$ and the inaccessible intersection point $R$ of the lines $a$ and $b$.

Task 2B may be solved in several ways. Therefore it is possible to rank Task 2B to two subtopics at minimum depending on the solving procedure:

Topic: Planimetry

Subtopic: Construction tasks

Element of subject matter:

Constructions of triangles

Constructions of rectangles

Didactic function:

tasks for strengthening the subject matter

tasks for revision and systematization of subject matter

Cognitive level: higher convergent processes

Topic: Planimetry

Subtopic: Identical and similar shapes

Element of subject matter: Homothety

Didactic function:

tasks for strengthening the subject matter

tasks for application of subject matter inside mathematics

tasks for revision and systematization of subject matter

Cognitive level: higher convergent processes

We find multiple occurrence of a task in the digest of tasks to be one of advantages of an electronic digest of tasks. Ranking one task to more than one topics, subtopics and elements of subject matter offers teachers a possibility to use the task at classes more times, and to make students to try solving the same task in several ways. It is more useful for mathematical thinking development to 


$$
\text { "mindakova" — 2007/8/9 — 13:44 — page } 15 \text { — \#15 }
$$

solve one task in several ways than more tasks of the same type in one way which is only a routine copying of the submitted pattern (see [8]).

The following example is to show how simply quality and openness of a task can be changed.

Task 3A: A car park has the area of $5000 \mathrm{~m}^{2}$. One parking place is $3 \mathrm{~m}$ wide and $5 \mathrm{~m}$ long. Driveways take about $40 \%$ of the car park area. How many parking places are there in the car park?

Classification of Task $\mathbf{3 A}$ according to appointed criteria:

Topic: Planimetry

Subtopic: Rectangles and polygons

Element of subject matter: Perimeters and areas of rectangles

Didactic function:

tasks for strengthening the subject matter

tasks for application of subject matter outside mathematics

tasks for revision and systematization of subject matter

Cognitive level: lower convergent processes

This typical school task may be reformulated as follows:

Task 3B: The car park is about as large as a football pitch. How many car places approximately is it possible to mark there? Give reasons for your considerations.

Classification of Task 3B in the digest:

Topic: Planimetry

Subtopic: Rectangles and polygons

Element of subject matter: Perimeters and areas of rectangles

Didactic function:

tasks for strengthening the subject matter

tasks for application of subject matter outside mathematics

tasks for revision and systematization of subject matter

Cognitive level:

evaluative thinking

creative, divergent thinking

Using a minimum demand we have set up an open task offering a great space for mathematics. While solving Task 3B, the students have to make up linkages between the knowledge of mathematics and experience of real life, they have to be able to estimate sizes, compare measures, count, make decisions and at the end to give reasons for their considerations. Classification of Task $\mathbf{3 A}$ according to 


$$
\text { "mindakova" — 2007/8/9 — 13:44 — page } 16 \text { — \#16 }
$$

the topic, subtopic, subject matter element and didactic function is in accordance with classification of Task 3B, nevertheless, Task 3B is more difficult than Task 3A. Task 3B develops evaluative thinking and creative, divergent thinking. Thus changing the openness of the task we have achieved a change of the cognitive level being developed by the task.

The following is a similar pair of tasks.

Task 4: Two candles are burning at different speed. The green candle burns down from $36 \mathrm{~cm}$ to $11 \mathrm{~cm}$ at constant speed in 5 hours. The red one burns down at constant speed from $10 \mathrm{~cm}$ to $8 \mathrm{~cm}$ in 2 hours.

Determine in what time these candles will be equally long.

Task 4 can be solved from the point of view of equations or from the point of view of functions. This is the basis for ranking Task 4 to more topics, subtopics or elements of subject matter, which confirms again the advantage of electronic digest of tasks - multiple occurrence of the task in the digest:

Topic: Equations, inequalities and their systems

Subtopic: Linear equations, inequalities and their systems

Element of subject matter:

Linear equations

Systems of linear equations

Word problems

\section{Didactic function:}

tasks for strengthening the subject matter

tasks for application of subject matter outside mathematics

tasks for revision and systematization of subject matter

Cognitive level:

lower convergent processes

higher convergent processes

Topic: Functions

Subtopic: Linear functions

Element of subject matter:

Definition of linear function, $D(f), H(f)$

Graphs of linear functions (also with abs. value), graph reading

Didactic function:

tasks for strengthening the subject matter

tasks for application of subject matter outside mathematics

tasks for revision and systematization of subject matter 


$$
\text { "mindakova" — 2007/8/9 — 13:44 — page } 17 \text { — \#17 }
$$

\section{Cognitive level:}

lower convergent processes

higher convergent processes

From the point of view of logical thinking development, Task 4 will become more interesting if we omit the condition in the setting that the candles are burning at constant speed. This modification of the condition will change the cognitive level of the task. The new task develops evaluative thinking as well as creative, divergent thinking, since students have to investigate more types of functions, watch the dependence of candle burning on time and assess possible proceedings of task solving.

\section{Change of the task plot}

Schupp's methods of context change and interface with practice can be seen in the connection with the method of task plot change.

By "plot" we understand a clue, a story of the task. Using this method of task reformulation either the classification will not get changed at all, or the task classification will be changed with regards to the didactic function. We will describe both of the possibilities later.

The simple "cover" of a purely mathematical task is, in fact, a change of the task plot. We will describe this procedure on the following pair of tasks.

Task 5A: Solve the system of equations in the set of real numbers:

$$
\begin{aligned}
& y=36-3 x, \\
& y=10-x .
\end{aligned}
$$

We rank a routine task from mathematical classes into the digest as follows:

Topic: Equations, inequalities and their systems

Subtopic: Linear equations, inequalities and their systems

Element of subject matter: Systems of linear equations

Didactic function: tasks for strengthening the subject matter

Cognitive level: lower convergent processes

Topic: Functions

Subtopic: Linear equation

Element of subject matter: Graphs of linear equations (also with abs. val.), graph reading 


$$
\text { "mindakova" — 2007/8/9 - 13:44 — page } 18 \text { — \#18 }
$$

Didactic function: tasks for strengthening the subject matter Cognitive level: lower convergent processes

Creating a story around mathematical facts in Task $\mathbf{5 A}$, we extend the set of didactic functions being developed by the task.

Task 5B: A green candle is $36 \mathrm{~cm}$ long and it is burning at linear speed of $3 \mathrm{~cm}$ per hour. A red candle is $10 \mathrm{~cm}$ long and it is burning at linear speed of $1 \mathrm{~cm}$ per hour. Form equations of the dependence of the candle's length $y \mathrm{~cm}$ on time $x$ hours. When are the candles going to be of the same length?

In the digest, Task 5B is ranked in the same way as Task 5A. Nevertheless, Task 5B can also fulfil motivating and application functions and therefore this task is also ranked to didactic functions of tasks for motivation of learning and cognitive activity of students and tasks for application of subject matter outside mathematics.

We can also watch this aspect at another pair of tasks:

Task 6A: Draw a set of all the points on the plane whose distance from the $A B$ abscissa $12 \mathrm{~cm}$ long is less or equal to $2 \mathrm{~cm}$.

Task 6B: Goats are known for grazing everything they can reach. Draw a shape grazed by a goat tethered as follows: a steel wire is stretched between 2 pegs that are $12 \mathrm{~m}$ apart, with a steel ring sleeved on so that the ring can run along the wire. A $2 \mathrm{~m}$ rope is tied to the ring, with the goat being tied to its other ending.

Tasks $6 \mathrm{~A}$ and $6 \mathrm{~B}$ may be ranked into the digest in the following way:

Topic: Planimetry

Subtopic: Constructional tasks

Element of subject matter: Sets of points of appointed qualities

Didactic function: tasks for strengthening the subject matter

Cognitive level:

lower convergent processes

higher convergent processes

At the same time, as in the preceding case, Task $\mathbf{6 B}$ can meet both the motivating and application functions therefore these two didactic functions were added when ranking this task.

At this change of the task plot it is necessary to avoid a violent and not always purposeful effort to create a story around mathematical model. Otherwise tasks may appear unnatural and they may be divorced from reality. 


$$
\text { "mindakova" — 2007/8/9 — 13:44 — page } 19 \text { — \#19 }
$$

The change of the task plot, however, does not have to change the classification of the task at all. In that case, this method is useful at the stage of adopting new knowledge. The task context change may sometimes help to understand the core of the task and to uncover "hidden" relations and connections.

Task 7A: A runner starts from $A$ to $B$. At the same time, a cyclist starts from $B$ to $A$ towards the runner. In what time will the runner meet the cyclist if it takes 12 minutes to the runner to run from $A$ to $B$, and it takes 8 minutes to the cyclist to get from $B$ to $A$ ?

Task 7B: In what time would two tractor drivers plough up a field if the first one would plough up this field on his own in 12 hours' time and the other one in 8 hours' time?

Task 7C: One cow devours a hay-cock in 12 minutes' time and the other one in 8 minutes' time. In what time can the two cows devour this hay-cock together?

Task 7D: One supply can fulfil a swimming-pool in 12 hours' time, the other one in 8 hours' time. In what time will the swimming-pool be fulfilled if it is being filled by both of the supplies at the same time?

The given group of tasks is ranked into the digest as follows:

Topic: Equations, inequalities and their systems

Subtopic: Equations, inequalities with the unknown in the denominator

Element of subject matter: Simple equations and inequalities (modification to linear and quadratic equations)

\section{Didactic function:}

tasks for motivation of learning and cognitive activity of students

tasks for acquiring the concept definition, theorem formulation, and solving procedure tasks for strengthening the subject matter

tasks for application of subject matter outside mathematics

\section{Cognitive level:}

lower convergent processes

higher convergent processes

It is possible to solve all the 4 tasks by the same equation with the unknown in the determiner. As we have already mentioned, it can be useful to use one task with various suggestions at the stage of adoption the knowledge. 


$$
\text { "mindakova" — 2007/8/9 — 13:44 — page } 20 \text { — \#20 }
$$

We apply the same principle on the following set of combinatorics tasks:

Task 8A: In the group of 7 people, everybody clinked their glasses with the others. How many clinks could be heard? (No two clinks merged into one).

Task 8B: 7 friends were parting. They were shaking each others' hands. How many hand-shakes were there?

Task 8C: How many different straight lines can be led through 7 points if no 3 points lie on one line?

Task 8D: 7 racers are running along a track. The first two advance to the finals. How many possibilities are there for the advancing pair?

Classification of this group of tasks in the digest is as follows:

Topic: Combinatorics

Subtopic: Basic concepts

Element of subject matter: Combinations

Didactic function:

tasks for motivation of learning and cognitive activity of students

tasks for acquiring the concept definition, theorem formulation, and solving procedure

tasks for strengthening the subject matter

tasks for application of subject matter outside mathematics

Cognitive level:

lower convergent processes

higher convergent processes

\section{Formation of reverse task}

The method of reverse task formation covers Schupp's methods of re-orientating, the task centre change and reversing.

Coming out of (see [11]) two notions are distinguished - converse and inverted task to the direct (original) task. The level of mathematic work of a student when solving a direct task and its converse version is usually equal. The student can even be able to solve a converse task without being able to solve the original task. The level of mathematic work at inverted tasks is higher than at direct tasks. The assumption for solving an inverted task is the knowledge of the original task solution. Sometimes the distinction of a converse task and inverted 


$$
\text { "mindakova" — 2007/8/9 — 13:44 — page } 21 \text { — \#21 }
$$

task from the given task is difficult (subjective), and it has no significant role for task reformulation. For that reason we have decided to call these tasks by one expression, i.e. reverse tasks to direct task.

This task reformulating is one of methods how to create open, divergent tasks and it is important from the point of view meeting developing aims of mathematics tuition (see [11]).

We will start with the description of this method of reformulation on a sample of classical task from mathematics tuition.

Task 9A: Find out if the graph of linear function $f: y=2 x-5, D(f)=R$ runs through the point $[2 ;-1]$.

Task 9B: Determine a real number $m$ in a way so that the graph of the function $f: y=2 x-5, D(f)=R$ runs through the point $[m ;-1]$.

Task 9C: Determine co-ordinates of at least one point the graph of the function $f: y=2 x-5, D(f)=R$ runs through.

Task 9D: Write an equation of a linear function whose graph runs through the point $[2 ;-1]$.

In the digest, the Tasks $\mathbf{9 A - 9 D}$ belong to:

Topic: Functions

Subtopic: Linear equation

Element of subject matter: Graphs of linear equations, graph reading

\section{Didactic function:}

tasks for strengthening the subject matter

tasks for revision and systematization of subject matter

\section{Cognitive level:}

lower convergent processes

higher convergent processes

Tasks 9A and 9B are convergent tasks tending towards the only possible correct solution. Tasks $\mathbf{9 C}$ and 9D involve a hint of divergence, and therefore these tasks can develop creative, divergent thinking. Tasks of similar type often occur at classes and after solving the first task of this kind, their function of creative thinking development might be disputable.

The following extract is a "characteristic" sample of divergent turned task formation:

Task 10A: 8 eggs cost SKK 32. How much are 12 eggs? 


$$
\text { "mindakova" — 2007/8/9 — 13:44 — page } 22 \text { — \#22 }
$$

We rank Task 10A to:

Topic: Functions

Subtopic: Linear function

Element of subject matter: Continual proportion

Didactic function:

tasks for strengthening the subject matter

tasks for application of subject matter outside mathematics

Cognitive level: lower convergent processes

Task 10B: Generate as many various tasks that can be solved by continual proportion as possible. Form tasks that cannot be solved by continual proportion.

Ranking Task 10B into the digest of tasks is the same as ranking Task 10A. Nevertheless, there is no only correct proceeding for task solution, nor a "correct" solution and for that reason we find this task to be a creative, divergent task; accordingly a level of creative, divergent thinking was added to cognitive levels.

If we went back to Task $\mathbf{6 B}$ about a goat, we could form the following turned task:

Task 11: How should we tethered the goat (by means of firm pegs, stretched wires and ropes) so that it could graze a geometrical shape shown in the picture (see Figure 2)? There may be several reasons for grazing these or other shapes, e.g. we do not want the goat to graze cabbage, to get drowned in the river, etc.
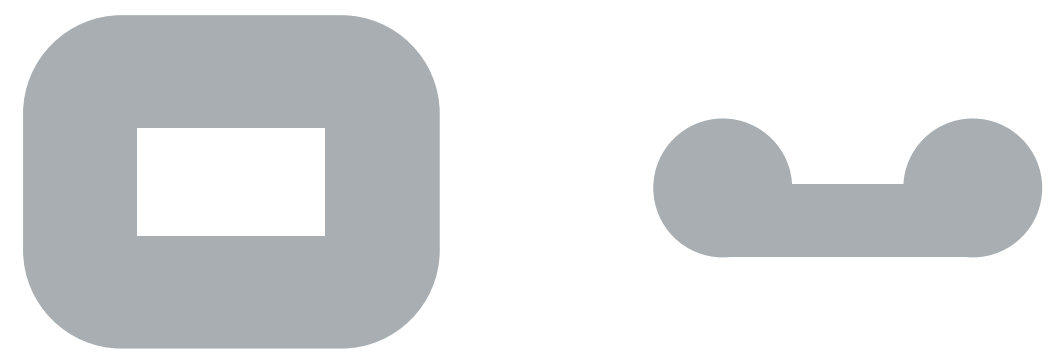

Figure 2

It is our experience that students have problems with uncovering and understanding the connections between an equation and a function graph. The 


$$
\text { "mindakova" — 2007/8/9 — 13:44 — page } 23 \text { - \#23 }
$$

following tasks also include interconnection with volume, and therefore the difficulty of these tasks is rather high. When solving the following mutually turned tasks, students can decide themselves how precisely they will take into regard "subtleties" of the candle burning graph or candle shape. This ambiguity of the task result irritates students.

Task 12A: Draw a graph showing burning of the candles in the picture (see Figure 3). (The dependence of the candle's length $y \mathrm{~cm}$ on time $x$ hours.)
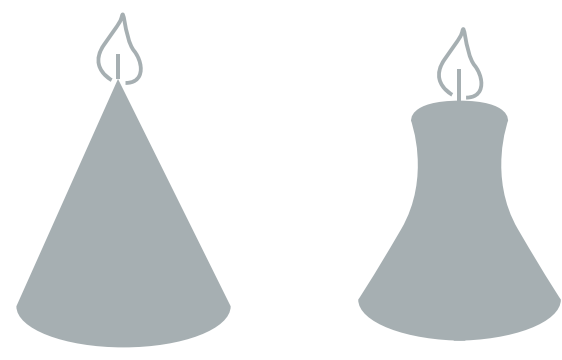

Figure 3

Task 12B: Draw a shape of the candle whose graph of burning is shown in the picture (see Figure 4). (The dependence of the candle's length $y$ cm on time $x$ hours.)

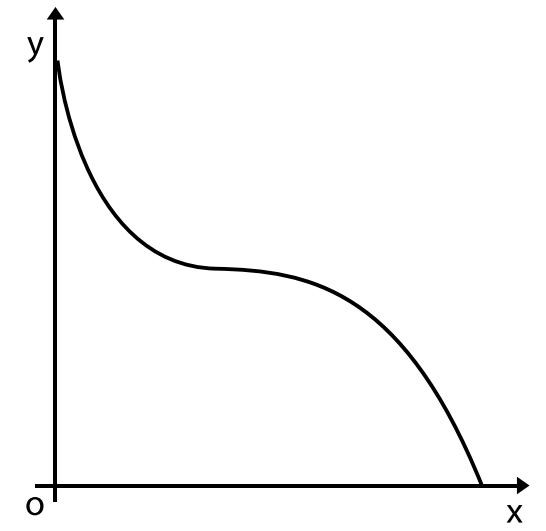

Figure 4 


$$
\text { "mindakova" — 2007/8/9 — 13:44 — page } 24 \text { — \#24 }
$$

Ranking of Task $\mathbf{1 2 A}$ and 12B into the digest of tasks:

\author{
Topic: Functions \\ Subtopic: Basic characterics of functions \\ Element of subject matter: Graph of function \\ Didactic function:
}

tasks for strengthening the subject matter

tasks for application of subject matter outside mathematics

tasks for revision and systematization of subject matter

\title{
Cognitive level: \\ higher convergent processes \\ evaluative thinking
}

If we go in the task reformulation a bit further, we can leave students themselves to reformulate tasks. In Task 11 they could suggest various shapes for the goat to graze or in Task 12A they could study different shapes of candles. Nevertheless, this problem goes beyond the framework of this article, and for that reason we will deal with it in some of our further articles.

\section{Experience of practice}

In order to show practical importance of electronic digest of tasks being formed, we decided to perform a pedagogical experiment. The aim of the survey was to test in school practice the usability of this digest and applicability of the task systems set up from the tasks of the electronic digest of tasks.

The experiment was performed at 7 grammar and secondary schools in Košice, Prešov and Michalovce. The experiment engaged 7 teachers who evaluated tasks and chosen criteria for task classification in the digest of tasks, and 9 teachers who were provided with the task systems set up from tasks of the digest. The teachers were submitted worksheets on the topic they were just teaching at their classes as well as matching methodical comments. It was their task to use the task systems for class preparation or directly at classes. The selection of the method of work with task systems was left to teachers themselves. The outputs of the experiment were questionnaires completed by teachers. Direct observation at classes where the systems were used was, along with debates with the teachers, a base for qualitative evaluation of the experiment.

Analysis of the survey results implies that the teachers find appointed criteria of task classification, especially ranking tasks according to didactic functions 
and cognitive levels, to be well-arranged and handy since they use the same or a very similar task classification themselves. The tasks in the digest are suitable for all types of secondary schools in Slovakia. The tasks were mostly assessed to be adequate for all the types of secondary schools though teachers of secondary apprentice schools had to modify the tasks a little to conditions in their classes. This only confirms the fact we have already mentioned in the section "Task systems" that there are no universally suitable task systems. Further, the teachers appreciated non-typical task formulations, heterogeneous types of tasks and last but not least detailed proceedings of task solutions. At the same time they remarked that the solved tasks considerably quicken everyday preparation for tuition.

\section{References}

[1] M. Bálintová, L. Burjanová, I. Viskupová, Secondary school mathematics in tests (Part 2), EXAM, Bratislava, 2004 (in Slovak).

[2] J. Baumert et al., TIMSS/III. The third international mathematic and science study, Berlin, 2000 (in German).

[3] B. S. Bloom, Learning aims taxonomy in cognitive area, Beltz, Weinheim, 1973 (in German).

[4] I. Bobovníková, Digest of mathematical tasks with $T_{E} X$, diploma thesis, PF UPJŠ, Košice, 1993 (in Slovak).

[5] A. Büchter and T. Leuders, Self production of mathematical tasks - Support the learning - Check the performance, Cornelsen Verlag Scriptor GmbH \& Co. KG, Berlin, 2005 (in German).

[6] L. Burjanová and I. Viskupová, Secondary school mathematics in tests (Part 1), EXAM, Bratislava, 2003 (in Slovak).

[7] M. Cirjak, Evaluation of students learning results, KPÚ, Bratislava, 1984 (in Slovak).

[8] M. Cirjak, Digest of divergent and other nonstandard tasks (creativity in mathematics), Essox, Prešov, 2000 (in Slovak).

[9] D. Dörner, Task solution as an information processing, Klett, Stuttgart, 1979 (in German).

[10] R. Dröge, Task solution appropriate for children, mathematik lehren 68 (1995), 8-12 (in German).

[11] P. M. Erdnijev, Task solution methods in mathematics, Prosveščenije, Moskva, 1970 (in Russian).

[12] M. Fečo, Digest of mathematical tasks on the PC, diploma thesis, PF UPJŠ, Košice, 1997 (in Slovak).

[13] H. E. Fischer and D. Draxler, Tasks and science tuition, Der Mathematische und naturwissenschaftliche Unterricht 54, no. 7 (2001), 388-393 (in German). 


$$
\text { "mindakova" — 2007/8/9 — 13:44 — page } 26 \text { — \#26 }
$$

[14] A. Franek and F. Zapletal, Thesis, questions and exercise in didactic of mathematics, Pedagogická fakulta UP, Olomouc, 1973 (in Czech).

[15] G. Glaeser, Didactic of mathematical Problems and Tasks, Vieweg, Braunschweig, 1980 (in German).

[16] D. Graf, What task types do exist?, Der mathematische und naturwissenschaftliche Unterricht 54, no. 7 (2001), 422-425 (in German).

[17] J. G. Greeno and H. A. Simon, Problem solving and reasoning, in: Stevens' handbook of experimental psychology, Vol. 2.: Learning and cognition, (R. C. Atkinson, R. J. Herrnstein, G. Lindzey, R. D. Luce, eds.), Wiley, New York, 1988.

[18] W. Herget, Task solution is enought ... isn't it!, mathematik lehren 100 (2000), 4-10 (in German).

[19] V. Hole, Successful mathematics tuition, Herderbücherei, Breisgan, 1973 (in German).

[20] J. Kopka, Groups of tasks in school mathematics, University of J. E. Purkynianae, Ústí nad Labem, 1999 (in Czech).

[21] F. Kuřina and Z. Pulpan, Questions and tasks in mathematics tuition, in: Matematika a fyzika ve škole, Vol. 17, 1987, 366-375 (in Czech).

[22] R. E. Mayer, Human nonadversary problem solving, in: Human and machine problem solving, (K. J. Gilhooly, ed.), Plenum, New York, 1989.

[23] I. Minďáková, Task systems for funcions and equations tuition, diploma thesis, PF UPJŠ, Košice, 2000 (in Slovak).

[24] I. Mindáková, Digest of mathematical tasks as a database, dissertation thesis, PF UPJŠ, Košice, 2002 (in Slovak).

[25] I. Mindáková and D. Šveda, Electronic digest of mathematical tasks and task systems, Matematika Informatika Fyzika 23 (2004), 127-130 (in Slovak).

[26] V. A. Oganesján and col., Didactic of school mathematics tuition, Prosveščenije, Moskva, 1980 (in Russian).

[27] K. Partiková and M. Reiterová, New school-leaving examination in mathematics 1, Príroda, Bratislava, 2005 (in Slovak).

[28] H. Schupp, Topic with variations, Franzbecker, Hildesheim, 2002 (in German).

[29] H. K. Strick, No fear from mixture tasks, Der Mathematische und naturwissenschaftliche Unterricht 51, no. 3 (1998), 144-151 (in German).

[30] H. K. Strick, Calculation story tasks for deeper handling of text tasks, Praxis der Mathematik in der Schule 37, no. 5 (1995), 197-200 (in German).

[31] H. K. Strick, From calculation scheme to calculation story tasks: Task clothing wanted!, mathematik lehren 81 (1997), 67 (in German).

[32] D. Šveda, Production of task systems in mathematics, Metodické centrum, Prešov, 1992 (in Slovak).

[33] M. Taulien, Ask the right questions, mathematik lehren 113 (2002), 11-13 (in German).

[34] M. Tücke, Psychology in the school - Psychology for the school, LIT, Münster, 1998 (in German). 


$$
\text { "mindakova" — 2007/8/9 — 13:44 — page } 27 \text { — \#27 }
$$

[35] V. Ulm, The mathematics tuition in secondary school open for individual learning methods, Kallmeyersche Verlagbuchhandlung GmbH, Seelze-Velber, 2005 (in German).

[36] V. Ulm, Methods for further development of mathematics tuition, Praxis der Mathematik 43, no. 4 (2001), 161-168 (in German).

[37] K. Ulshöfer, Create the tasks yourself!, Mathematik in der Schule 36, no. 12 (1998), 643-650 (in German).

[38] J. Vyšín, Three captures about the problem-oriented mathematics tuition, SPN, Praha, 1972 (in Czech).

[39] W. Walsch, Task families (Part 1), Mathematik in der Schule, 33, no. 2 (1995), 78-82 and 33, no. 3 (1995), 142-152 (in German).

[40] G. Walther, Simple task - and what can the teacher learn out of it for the problem-oriented tuition, Didaktik der Mathematik 4 (1985), 295-302 (in German).

[41] M. Zelina, Creativity in school mathematics, education material, Bratislava, 1990 (in Slovak).

INGRID MINĎÁKOVÁ

GEORG-MASEL-STRASSE 14

95463 BINDLACH

GERMANY

E-mail: mindakova@gmail.com

(Received November, 2005) 